\title{
RECONHECIMENTO LEXICAL DE ESTUDANTES DE FISIOTERAPIA DURANTE LEITURA DA CLASSIFICAÇÃO INTERNACIONAL DE FUNCIONALIDADE, INCAPACIDADE E SAÚDE
}

\author{
LEXICAL RECOGNITION OF PHYSICAL THERAPY STUDENTS DURING A READING OF \\ THE INTERNATIONAL CLASSIFICATION OF FUNCTIONING, DISABILITY AND HEALTH
}

\section{Andressa da Silva Palmeira Paulo Henrique Ferreira de Araújo-Barbosa Emerson Fachin-Martins}

Faculdade de Ceilândia Universidade de Brasília

\author{
Contato \\ Emerson Fachin-Martins \\ Campus Universitário Darcy Ribeiro \\ Setor Colina, Bloco J/604 \\ Asa Norte \\ Brasília - DF \\ CEP: 70.904-110 \\ E-mail: emersonntaai@gmail.com
}

\section{RESUMO}

Objetivo: Dimensionar o reconhecimento de vocábulos por estudantes de fisioterapia durante leitura da Classificação Internacional de Funcionalidade, Incapacidade e Saúde (CIF) e propor estratégias de enriquecimento lexical a partir dos vocábulos desconhecidos apreendidos com o intuito de treinar habilidades e competências descritivas de estados de saúde individuais e populacionais. Método: O conteúdo da CIF foi fragmentado em 9 trechos consecutivos de aproximadamente 30 páginas cada. Para cada trecho, um grupo de estudantes foi formado para a leitura e declaração de vocábulos desconhecidos. Os estudantes tinham a escolha de sugerir um significado para o vocábulo desconhecido caso desejassem. Posteriormente, os vocábulos e os seus significados sugeridos, quando anotados, foram analisados por dois julgadores cegos que verificaram o significado descrito pelo estudante com o significado real. Discordâncias foram decididas por um terceiro julgador. Resultados: A amostra foi composta por 37 estudantes com 19,8 $\pm 1,5$ (média \pm DP) anos de idade que declararam 167 vocábulos como desconhecidos. Os vocábulos foram desconhecidos por no mínimo 1 e no máximo 16 estudantes. Dos estudantes que declararam vocábulos desconhecidos, $30 \%$ arriscaram colocar um possível significado, porém somente $18 \%$ deles aproximaram o significado anotado do significado real. Os trechos 3, 4 e 9 foram aqueles com maior número de vocábulos desconhecidos. Conclusões: Conclui-se que a CIF possui quase duas centenas de vocábulos desconhecidos por estudantes de fisioterapia, os quais estão concentrados no interior e no final do documento. Sugere-se um glossário contendo os 167 vocábulos para enriquecimento lexical de futuros leitores.

Palavras-chave: Compreensão. Classificações. Dicionário. Fisioterapia. 
Objective: To scale the word recognition of physical therapy students during a reading from International Classification ofFunctioning, Disability and Health (ICF) and to propose lexical enrichment strategies for unknown apprehended vocabulary in order to develop skills and competencies to describe individual and populational health status. Method: ICF content was fragmented in 9 consecutive sets of approximately 30 pages each. For each set, a group of students was composed for the reading and statement of unknown words. When an unknown word was identified, the reading was interrupted, and the word written down. The students had the choice to suggest a meaning to the unknown word if desired. Later, the words and their suggested meanings, were analyzed by two blind judges who evaluated the declared meaning with the real one. Disagreements were decided by a third judge. Results: The sample consisted of 37 students who were $19.8 \pm 1.5$ (mean \pm SD) years old who declared 167 words as unknown. The words were unknown for a maximum of 16 and at least one students. Out of the students who declared not knowing words, $30 \%$ risked putting one possible meaning, but only $18 \%$ of them approached their meaning to the real meaning. Sections 3 , 4 and 9 were the segments with the highest number of unknown words. Conclusions: The ICF has nearly two hundred words unknown to physical therapy students and these are concentrated in the middle and in the end of the document. We recommend a glossary composed by the 167 words as lexical enrichment for future students.

Keywords: Comprehension. Classification. Dictionary. Physical Therapy Specialty.

\section{INTRODUÇÃO}

A Classificação Internacional de Funcionalidade, Incapacidade e Saúde (CIF) foi concebida em um documento textual cuja versão publicada em 2001 pela Organização Mundial da Saúde (OMS) corresponde a um aprimoramento da versão anterior conhecida por Classificação Internacional de Deficiências, Incapacidades e Desvantagens (CIDID). O conteúdo textual, aprovado por padrões de descrição mundiais, adotou o modelo de atenção biopsicossocial que dispõe sobre a combinação de concepções biológicas, sociais e pessoais para informar sobre saúde de indivíduos e populações em seu discurso ${ }^{1}$.

Diferentemente da forma como a CIDID foi textualmente concebida, a CIF apoiou sua organização taxonômica em um modelo de estado de saúde integrado por determinantes presentes em quatro componentes: (1) funções do corpo, (2) estruturas do corpo, (3) atividades e participação e (4) fatores contextuais (pessoais e ambientais). Ainda na sistematização da organização dessa forma de classificação, adotou-se a estratégia de qualificação dos códigos, que transformam os determinantes do estado de saúde em códigos neutros que, somente quando qualificados, permitem identificar se tal determinante de saúde (código) informa um aspecto positivo (funcionalidade no seu sentido stricto) ou negativo (incapacidade) do estado de saúde (funcionalidade no seu sentido lato) (1,2,3. $^{1}$

A CIF não foi criada com o propósito de substituir a Classificação Internacional de Doenças (CID), outro documento textual que já se encontra na décima versão e já integrado ao Departamento de Informática do Sistema Único de Saúde (DATASUS), mas, sim, para complementar os indicadores de saúde que possuem um grande foco em óbitos e doenças, não abrangendo contextos ambientais, sociais e individuais (não biológicos) que também interferem no estado de saúde do indivíduo e ampliam a visão puramente biológica desse estado ${ }^{4}$.

A CIF aponta em seu objetivo mais universal proporcionar uma linguagem padronizada para promover a compreensão e fomentar estudo dos determinantes da saúde, instituindo uma linguagem comum e unificada entre os profissionais de todas as categorias e em todo o mundo. Acompanhando 
esse objetivo universal, observam-se na literatura científica, desde sua publicação em 2001, inúmeras propostas de incorporação do racional presente na CIF em práticas assistenciais e gerenciais em saúde ${ }^{3}$.

O modelo de organização taxonômica qualificável da CIF permite seu uso de forma multidirecional, ocasião em que os fatores ambientais, sociais e pessoais se inter-relacionam com o fator biológico na caracterização de um estado de saúde dado pelo balanço entre determinantes de funcionalidade ou de incapacidade. Logo, o modelo utilizado também permite que a caracterização em códigos qualificáveis seja aplicável para levantamento de dados epidemiológicos e de dados que contribuem para a gestão de recursos humanos em diversos setores da sociedade ${ }^{2,5}$.

No decorrer das páginas do texto que compõe o manual de utilização da CIF, podemos encontrar cerca de 1.454 códigos descritos em maior (microinformação) ou menor (macroinformação) detalhamento do determinante de saúde, por meio de vocábulos muitas vezes desconhecidos por quem o utiliza, o que poderia dificultar o seu uso, bem como a boa compreensão e interpretação das descrições que clarificam os códigos atribuídos aos determinantes, comprometendo assim a adequada qualificação do código que só será alcançada, caso o vocabulário receptivo dos leitores abranja a totalidade e a especificidade lexical encontradas nesse texto ${ }^{1}$.

De acordo com Pedrosa, Dourado e Lemos ${ }^{6}$, cada indivíduo se comunica por meio de uma coleção de palavras de sua determinada língua, proferindo assim o vocabulário expressivo, que está embasado no vocabulário receptivo que se aprimora com o avançar dos anos e está relacionado com a percepção e o processamento de informação. Esses processos comunicativos vão acontecer pela aquisição da linguagem que ocorre durante o desenvolvimento cognitivo e origina a capacidade de compreensão dos conceitos, bem como dos seus significados perante a leitura das palavras ${ }^{6}$. Assim, o processo comunicativo se inicia com o nascimento e perdura por todo o ciclo de vida humano.
Nesse contexto, a junção dos processos de formação do léxico é denominada como desenvolvimento lexical, mantendo uma inter-relação progressiva com as experiências sociointeracionais do ambiente onde o indivíduo está inserido e contextualizado, que se aperfeiçoam por toda a vida. Ou seja, o desenvolvimento do conjunto de vocabulários receptivos e de campos lexicais distintos serão aprimorados pelas experiências vividas que constantemente apresentarão novas palavras a serem incorporadas no conjunto da obra lexical $^{6}$.

Especialistas são concordantes em reconhecer que o desenvolvimento de vocabulários receptivos é essencial para incrementar o vocabulário expressivo e a capacidade de compreender e expressar em campos lexicais distintos ${ }^{6,7}$. Em particular no campo lexical da saúde, a aquisição de uma linguagem precisa, coerente e própria para descrever condições e estados de saúde é habilidade e competência desejadas para um fisioterapeuta ${ }^{2}$.

Em consulta nacional promovida no âmbito da Associação Brasileira de Ensino em Fisioterapia (ABENFISIO) para reformulação das Diretrizes Curriculares Nacionais (DCN) dos Cursos de Fisioterapia, que foi sancionada pela Resolução CNE/CES 4, de 19 de fevereiro de $2002^{8,9}$ e apresentada no XXVI Fórum Nacional de Ensino em Fisioterapia de 2016; a preocupação com a aquisição de linguagem foi citada como dimensão a ser incorporada na formação de fisioterapeutas pelo Brasil, reforçando assim a necessidade de explorarmos melhor os vocabulários reconhecidos pelos estudantes de fisioterapia.

A aquisição do vocabulário receptivo está relacionada com o aperfeiçoamento da linguagem e de processos cognitivos que capacitam na inferência de significados e na atribuição de sentidos de forma automática quando palavras desconhecidas aparecem em um texto lido. Tais processos aprimoram a compreensão, definida por Nalom et al. ${ }^{10}$ como a habilidade de indivíduos interpretarem e integrarem o conteúdo do material lido por meio de memória e inferência. Dessa forma, a leitura de materiais oferecidos no decorrer da formação de 
estudantes universitários estaria gradativamente acrescentando novos vocábulos que agregariam informações que somente serão internalizadas em seu intelecto, quando apoiada na compreensão receptiva ou na consulta a glossários ${ }^{10}$.

Embora o senso comum considere a compreensão um sinônimo de fluência, os conceitos são distintos, e ambos fazem parte do processo de aprendizagem na leitura de novos vocábulos. Segundo Nalom et al. ${ }^{10}$, a fluência precede a compreensão com a habilidade de reconhecer as palavras, ou, de acordo com Salles e Parente ${ }^{11}$, é uma atividade complexa imposta de diversos processos cognitivos inter-relacionados, dos quais os primordiais seriam o reconhecimento de palavras ao acessar o léxico mental individual e a compreensão textual escrita que se fundamenta na elaboração de inferências alicerçadas nas habilidades linguísticas gerais, na memória, nos conhecimentos gerais a respeito do mundo que unidos fornecem uma reprodução macroestrutural do texto no imaginário do leitor $7: 10$.

Entretanto, tal habilidade de reconhecimento automático dos vocábulos no contexto de leitura pode não ser habilidade presente em todos os estudantes universitários. Cada vez mais, é possível identificar no meio universitário a presença do que se conhece popularmente por analfabetismo funcional ${ }^{12}$. A Organização das Nações Unidas para a Educação, a Ciência e a Cultura (UNESCO) define analfabetismo funcional como sendo uma inabilidade observada em um indivíduo que consegue ler as letras, palavras e frases isoladas, mas que não é capaz de explicar o sentido do texto ${ }^{12}$. No Brasil, o Indicador de Alfabetismo Funcional (INAF), com apoio do Instituto Brasileiro de Opinião e Estatística (IBOPE), apresentou que, em 2011, o analfabetismo funcional alcançou a marca de $27 \%$ das pessoas entre 15 e 64 anos de idade. O mais surpreendente foi notar que, dos classificados como analfabetos funcionais, $4 \%$ possuíam nível superior ${ }^{13}$.

Dada a diversidade de estratégias de aprendizagem em que as experiências vividas por estudantes universitários de fisioterapia assumem na aquisição de vocabulário, avaliar o reconhecimento lexical receptivo dos estudantes em formação, em um documento textual mundialmente reconhecido, configura-se como estratégia didática e aumentativa do campo lexical. De um lado, temos a possibilidade de obter um panorama do conjunto de vocábulos que representam um desafio lexical durante a leitura do texto presente na CIF para os estudantes em formação; de outro, a possibilidade de ofertar um glossário específico dos vocábulos mais desconhecidos para favorecer a aquisição de uma memória lexical para aqueles que não conseguiriam inferir significado de forma automática durante a leitura. Ante o exposto, o trabalho teve como objetivo dimensionar o desconhecimento de vocabulário receptivo de estudantes de fisioterapia durante leitura textual da CIF.

\section{MÉTODOS}

O presente estudo aconteceu no âmbito da disciplina denominada Funcionalidade e Saúde que é ofertada para o curso de graduação em Fisioterapia da Faculdade de Ceilândia (FCE) da Universidade de Brasília (UnB). A disciplina tem por objetivo descrever os componentes relacionados com a saúde e com o bem-estar, apresentando modelos de funcionalidade e incapacidade que permitam uma melhor identificação do papel do fisioterapeuta em todos os níveis de atenção à saúde. Nesse contexto, conceitos e conteúdos são incorporados na prática de descrição de estados de saúde tanto na recepção quanto na expressão da linguagem oral e/ou escrita no campo lexical da saúde em um cenário de formação e educação permanente.

A disciplina tem como foco a apreensão de conteúdos extraídos em discursos orais e escritos, bem como o treinamento de habilidades e competências para descrever e compreender documentos textuais para relatar estados de saúde 
de um indivíduo ou de uma população. Uma vez adotado o modelo de estado de saúde proposto na CIF e instrumentalizado o uso combinado das Classificações Internacionais como ferramenta para sistemas de informação em saúde, a disciplina tornase também um espaço para discutir linguagem e sistemas de informação.

$O$ interesse de dimensionar o desconhecimento do vocabulário receptivo durante a leitura da CIF surgiu da proposta de utilizar os vocábulos desconhecidos em estratégias metacognitivas de enriquecimento lexical que proporcionaria o treinamento de habilidades e competências para descrever estados de saúde individuais e populacionais. Também teve a intenção de formar um glossário para consulta em um software de codificação e qualificação de informações sobre os estados de saúde que está sendo desenvolvido no âmbito do time de pesquisa INFOSAÚDE - Funcionalidade e Informação em Saúde. Este time de pesquisa faz parte da equipe TECSAÚDE - Tecnologias Diagnósticas, Terapêuticas e Assistenciais em Saúde que compõe com outras equipes o NTAAI - Núcleo de Tecnologia Assistiva, Acessibilidade e Inovação da Universidade de Brasília (http://www.ntaai.unb.br/).

A pesquisa caracterizou-se como um estudo transversal, empírico e qualiquantitativo, visto que a utilização conjunta de métodos quantitativos e qualitativos não são excludentes, mas, sim, complementares $^{14,15}$. Essa visão é centrada na explicação de um fenômeno por meio de métodos quantitativos; e o seu significado, pelos qualitativos, abrangendo um maior cenário a depender do intuito do pesquisador. $O$ presente projeto foi aprovado pelo Comitê de Ética em Pesquisa da Faculdade de Ciências da Saúde (CEP/FS) da UnB pelo número CAAE: 45148215.1.0000.0030. Todos os participantes assinaram o Termo de Consentimento Livre e Esclarecido (TCLE); após, receberem orientação dos procedimentos que foram aplicados na pesquisa e posteriormente a concordância em participar.
O curso de Fisioterapia da FCE da UnB possui principalmente estudantes ingressos por meio do Vestibular, do Programa de Avaliação Seriada (PAS) e do Exame Nacional do Ensino Médio (ENEM). No ano de 2014, 102 pessoas no $1^{\circ}$ e $2^{\circ}$ semestres ingressaram no curso de Fisioterapia, sendo que, destes, 53 ingressaram no 1\%/2014 e 49 no 2\%/2014. Nesse mesmo ano, 29 estudantes colaram grau, perfazendo uma quantidade de 12 egressos no 1\%/2014 e 17 egressos no $2^{\circ} / 2014^{16}$.

Participaram da pesquisa uma amostra de conveniência $(n=37)$ formada por todos os estudantes de Fisioterapia regularmente matriculados na disciplina supracitada e que estavam presentes na aula no momento da avaliação (não mencionaremos o período da coleta de dados para manter a confidencialidade dos estudantes pesquisados).

Foi realizado um teste de leitura oral controlado de palavras contextualizadas no próprio texto do documento fonte: a CIF, para identificar o desconhecimento no campo lexical desse documento. Partimos do pressuposto que todos os estudantes encontravam-se no mesmo nível de compreensão lexical, dado que, em sua maioria, adentraram no mesmo semestre no curso de Fisioterapia e estariam expostos a experiências didático-pedagógicas similares até então.

A CIF, em sua versão na língua portuguesa falada no Brasil, foi fragmentada sequencialmente em 9 trechos consecutivos de aproximadamente 30 páginas cada um. Cada trecho foi distribuído para leitura por um dos integrantes de cada grupo (orador), de um total de 9 grupos, dos quais 8 deles eram compostos por 4 estudantes, e 1, por 5 estudantes.

Cada estudante recebeu um formulário para declarar vocábulos desconhecidos que seriam identificados no momento da leitura pelo orador do grupo. O processo de leitura ocorreu no período de duração da disciplina de 4 horas com intervalo de aproximadamente 15 minutos entre cada metade do período total (2 horas). O professor responsável pela disciplina estava presente na sala de aula assistindo 
aos grupos e dando as orientações sobre a leitura dos trechos da CIF.

Uma vez iniciada a leitura, a cada vocábulo desconhecido identificado por um dos integrantes do grupo, a leitura era interrompida pelo orador para que o integrante com dúvida anotasse o vocábulo, ou, periodicamente, quando o professor identificava uma queda na capacidade de atenção dos grupos, para que retomassem a atenção. Nesse mesmo formulário, o estudante poderia também anotar um possível significado, caso ele desejasse.

Posteriormente, os vocábulos e seus prováveis significados, quando anotados por desejo do estudante, foram analisados por dois julgadores independentes que verificaram a aproximação do significado apresentado pelo estudante com o significado real do vocábulo. Os julgadores analisaram os possíveis significados nos diferentes contextos que o vocábulo pode ser empregado conforme consulta ao dicionário Michaelis disponível on-line. As discordâncias encontradas entre os julgadores foram decididas por um terceiro julgador.

Os resultados foram então processados e apresentados por meio da média, desvio padrão e moda, em planilhas do programa Microsoft $®$ Excel 2010. A ANOVA - Análise de Variância com pósteste de Duncan - foi também empregada para comparar a quantidade de vocábulos desconhecidos em comparações entre os 9 trechos por grupos que realizaram o teste de leitura. Estabeleceu-se $p<0,05$ para considerar diferenças estatisticamente significativas nas análises. Para a análise qualitativa, foi realizada uma análise de conteúdo que permitiu a apreensão dos vocábulos desconhecidos e seus prováveis significados ao longo dos respectivos trechos fragmentados da $\mathrm{CIF}^{15}$.

\section{RESULTADOS}

A média geral de idade dos estudantes avaliados foi de 19,8 $\pm 1,5$ (média \pm DP), com idade mínima de 18 e máxima de 24 anos. Dos estudantes considerados na pesquisa, $33(89,1 \%)$ ingressaram na UnB no período de 2/2013 (fluxo regular de oferta); e $4(10,9 \%)$ ingressaram em outros períodos (estudantes fora do fluxo por motivo de reprovação ou trancamento da disciplina). A média total de vocábulos desconhecidos foi de 14,5 vocábulos por grupo, tendo o grupo 4, que realizou a leitura do Trecho 4 (T4), relatado a maior quantidade de vocábulos desconhecidos (42 vocábulos).

Em todos os 9 trechos da CIF, 167 vocábulos foram declarados como desconhecidos por pelo menos um estudante entre os presentes por grupo, vocábulos estes que estão listados nos quadros da figura 1. As tabelas agruparam vocábulos qualificados conforme a separação pela moda de estudantes que relataram dúvida por vocábulo.

A lógica de separação pelas tabelas levou em consideração que a moda de estudantes que não reconheceram o vocábulo, ou seja, um vocábulo não ter sido reconhecido por 4 estudantes, representou o ponto divisor (quadro central da figura 1) da quantidade de estudantes para determinar se um vocábulo seria mais desconhecido (não ser reconhecido por mais de 4 estudantes, quadro da esquerda da figura 1) ou menos desconhecido (não ser reconhecido por menos de 4 estudantes, quadro da direita da figura 1).

Figura 1. Quadros com vocábulos desconhecidos nos trechos fragmentados da CIF agrupados pela moda de estudantes que desconheciam o vocábulo em três grupos

\section{Vocábulos mais desconhecidos}

\begin{tabular}{|c|}
\hline acuidade \\
alopática \\
constructo \\
doravante \\
empirico \\
estigma \\
percentis \\
sazonal \\
timbre \\
treinadores auditivos de FM \\
\hline 10 vocábulos
\end{tabular}

10 vocábulos 
Vocábulos desconhecidos pela moda de estudantes

\begin{tabular}{|c|c|c|c|}
\hline $\begin{array}{c}\text { aerofagia } \\
\text { afasia } \\
\text { agalactia } \\
\text { alactasia } \\
\text { algoritmo } \\
\text { alodinia } \\
\text { amenorréia } \\
\text { anopsia } \\
\text { atenuar } \\
\text { atetose } \\
\text { azoospermia } \\
\text { catatonia } \\
\text { circularidade } \\
\text { detrimento } \\
\text { dialética } \\
\text { diplopia } \\
\text { discinesia } \\
\text { disdiadococinesia } \\
\text { disfagia } \\
\text { ecolalia }\end{array}$ & $\begin{array}{c}\text { elegibilidade } \\
\text { eletrolitico } \\
\text { eletro-óptico } \\
\text { emaciação } \\
\text { empachamento } \\
\text { endossa } \\
\text { ergonomia } \\
\text { escopo } \\
\text { escotoma } \\
\text { estupor } \\
\text { extrinseco } \\
\text { galactorréia } \\
\text { gama } \\
\text { genuíno } \\
\text { handicap } \\
\text { hematológico } \\
\text { hemianopsia } \\
\text { hidrâmnios } \\
\text { hidronefrose }\end{array}$ & $\begin{array}{c}\text { hipernatremia } \\
\text { hipogonadismo } \\
\text { hiponatremia } \\
\text { hipopituitarismo } \\
\text { holisticamente } \\
\text { idiomática } \\
\text { inerente } \\
\text { labilidade } \\
\text { litigios } \\
\text { melodiosidade } \\
\text { mitigando } \\
\text { mutismo } \\
\text { nistagmo } \\
\text { obnubilação } \\
\text { obstante } \\
\text { oligozoospermia } \\
\text { oligúria } \\
\text { peristaltismo } \\
\text { permutas }\end{array}$ & $\begin{array}{c}\text { prefácio } \\
\text { priapismo } \\
\text { protético } \\
\text { ptose } \\
\text { redundância } \\
\text { riquixá } \\
\text { saneamento } \\
\text { sáris } \\
\text { simbolo bliss } \\
\text { subsidios } \\
\text { taxonômica } \\
\text { teletipos } \\
\text { terminologia } \\
\text { tom } \\
\text { univoca } \\
\text { urge } \\
\text { verborréia } \\
\text { verter } \\
\text { xeroftalmia }\end{array}$ \\
\hline
\end{tabular}

77 vocábulos

Vocábulos menos desconhecidos

\begin{tabular}{|c|c|c|c|}
\hline $\begin{array}{c}\text { acinético } \\
\text { alopecia } \\
\text { ambigua } \\
\text { ambivalência } \\
\text { anúria } \\
\text { àreas anexas } \\
\text { aspereza } \\
\text { assimilaçäo } \\
\text { assoalho pélvico } \\
\text { atitudinal } \\
\text { caçarola } \\
\text { calibrado } \\
\text { caquexia } \\
\text { ciclomotores } \\
\text { claudicaçäo } \\
\text { closed caption } \\
\text { codificador } \\
\text { conotação } \\
\text { contextuais } \\
\text { coprolalia }\end{array}$ & $\begin{array}{c}\text { coreia } \\
\text { corióide } \\
\text { debilidade } \\
\text { descontinuidade } \\
\text { dismenorréia } \\
\text { dispareunia } \\
\text { distonia } \\
\text { distônico } \\
\text { ducto cistico } \\
\text { ecopraxia } \\
\text { ectópica } \\
\text { escalão } \\
\text { escaras } \\
\text { esclera } \\
\text { espasmo } \\
\text { espasmódica } \\
\text { etiologia } \\
\text { excludentes } \\
\text { exteroceptivos } \\
\text { filiaçäo }\end{array}$ & $\begin{array}{c}\text { frigidez } \\
\text { geniturinárias } \\
\text { gerenciar } \\
\text { hipercalcemia } \\
\text { hipermenorrèia } \\
\text { hipermortilidade } \\
\text { hiperpituitarismo } \\
\text { hiperpotassamia } \\
\text { hipocalcemia } \\
\text { hipotônico } \\
\text { hipotossemia } \\
\text { literal } \\
\text { manufaturada } \\
\text { menorragia } \\
\text { mialgia } \\
\text { miastenia } \\
\text { miç̧ão } \\
\text { monoparesia } \\
\text { monoplegia } \\
\text { Narcolepsia } \\
\end{array}$ & $\begin{array}{c}\text { orografia } \\
\text { ortopédico } \\
\text { polimenorragia } \\
\text { poliúria } \\
\text { prostrado } \\
\text { protração } \\
\text { Provêem } \\
\text { provisão } \\
\text { psicossociais } \\
\text { regurgitar } \\
\text { remendar } \\
\text { retração } \\
\text { sacádicos } \\
\text { sintese } \\
\text { subfertilidade } \\
\text { supina } \\
\text { tartamudez } \\
\text { terminológicas } \\
\text { vernaculares } \\
\text { vernaculistas }\end{array}$ \\
\hline
\end{tabular}

80 vocábulos 
Os vocábulos desconhecidos dispostos na figura 1 encontravam-se distribuídos em todos os trechos fragmentados. No entanto, os trechos com maior quantidade de vocábulos desconhecidos foram os trechos 3, 4 e 9 (Figura 2), indicando o menor reconhecimento lexical nesses respectivos trechos da CIF.

Os vocábulos desconhecidos pela moda de estudantes dispostos no quadro central da figura 1 também se encontravam distribuídos em todos os trechos fragmentados. Todavia, para os vocábulos classificados como menos desconhecidos por estudantes (quadro da direita na figura 1), somente o trecho 4 apresentou uma maior quantidade de vocábulos declarados como desconhecidos. Já no quadro da esquerda da figura 1 , que representa os vocábulos mais desconhecidos por estudantes, os vocábulos estavam distribuídos em 7 dos 9 trechos fragmentados da CIF, sendo exceção somente os trechos 5 e 6 .

Nesse contexto, foi constatado maior desconhecimento lexical nos trechos 7 (com 4 vocábulos), seguido dos trechos 2, 8 e 9 com 2 vocábulos cada, de um total de 10 vocábulos desconhecidos por mais de 4 estudantes. A caracterização dos trechos consecutivos e fragmentados de aproximadamente 30 páginas cada um, na CIF em sua versão na língua portuguesa falada no Brasil, está demonstrada na tabela 1.

Figura 2. Box-plots da quantidade de vocábulos declarados como desconhecidos por pelo menos 1 estudante em todos os trechos consecutivamente distribuídos aos nove grupos da amostra. As setas indicam as diferenças significativas identificadas pela ANOVA seguida do pós-teste de Duncan

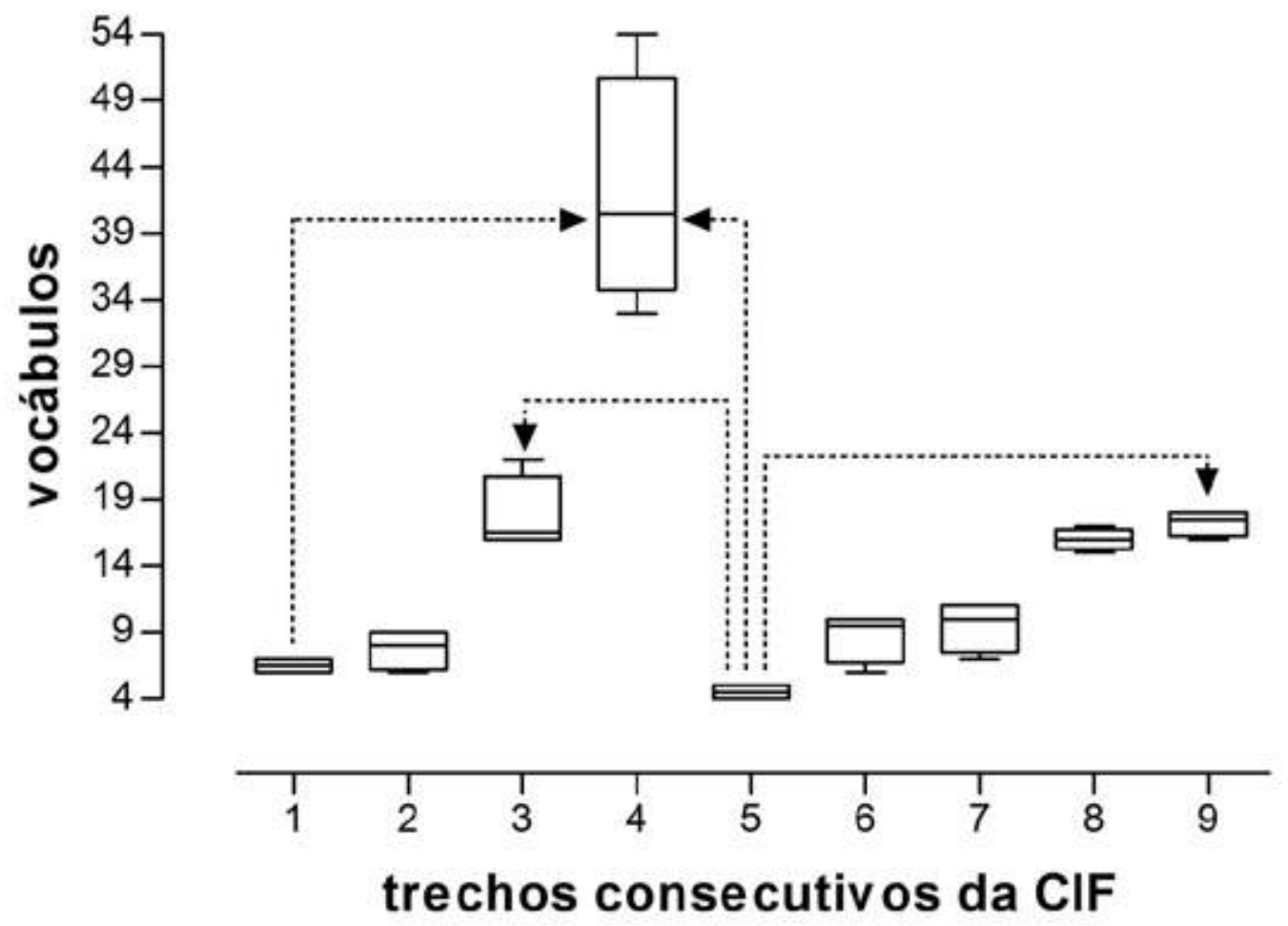


Tabela 1. Caracterização dos conteúdos por páginas e trechos distribuídos por grupos de estudantes

\begin{tabular}{|c|c|l|}
\hline Trechos & Páginas & \multicolumn{1}{|c|}{ Conteúdo } \\
\hline $\begin{array}{c}\text { Trecho 1 } \\
\text { (T1) }\end{array}$ & 0 a 32 & $\begin{array}{l}\text { Capa e contracapa, folha de rosto, } \\
\text { sumário e introdução }\end{array}$ \\
\hline $\begin{array}{c}\text { Trecho } 2 \\
\text { (T2) }\end{array}$ & 33 a 60 & $\begin{array}{l}\text { Usos da CIF, classificação de primeiro e } \\
\text { segundo nível }\end{array}$ \\
\hline $\begin{array}{c}\text { Trecho } 3 \\
\text { (T3) }\end{array}$ & 61 a 98 & $\begin{array}{l}\text { Classificação detalhada com definiç̃̃es: } \\
\text { funções do corpo (até o Capítulo 4) }\end{array}$ \\
\hline $\begin{array}{c}\text { Trecho } 4 \\
\text { (T4) }\end{array}$ & 99 a 130 & $\begin{array}{l}\text { Funções do corpo (do Capítulo 5 ao 8) e } \\
\text { estruturas do corpo (Capítulos 1 e 2) }\end{array}$ \\
\hline $\begin{array}{c}\text { Trecho } 5 \\
\text { (T5) }\end{array}$ & 131 a 161 & $\begin{array}{l}\text { Estruturas do corpo (do Capítulo 3 ao 8), } \\
\text { atividades e participação (até o Capítulo 3) }\end{array}$ \\
\hline $\begin{array}{c}\text { Trecho } 6 \\
\text { (T6) }\end{array}$ & 162 a 198 & $\begin{array}{l}\text { Atividades e participação (do Capítulo 4 ao } \\
\text { 9) }\end{array}$ \\
\hline $\begin{array}{c}\text { Trecho } 7 \\
\text { (T7) }\end{array}$ & 199 a 222 & Fatores ambientais (até o Capítulo 4) \\
\hline $\begin{array}{c}\text { Trecho } 8 \\
\text { (T8) }\end{array}$ & 223 a 262 & $\begin{array}{l}\text { Fatores ambientais (Capítulo 5) e anexos } \\
\text { e 2 }\end{array}$ \\
\hline $\begin{array}{c}\text { Trecho } 9 \\
\text { (T9) }\end{array}$ & 263 a 296 & Anexos 3 ao 10 \\
\hline
\end{tabular}

Os vocábulos foram desconhecidos por no mínimo 1 e no máximo 16 estudantes. Dos estudantes que declararam vocábulos desconhecidos, $30 \%$ arriscaram colocar um possível significado, porém somente $18 \%$ deles aproximaram o significado anotado do significado real. Os trechos 3,4 e 9 foram os trechos com maior número de vocábulos desconhecidos, havendo diferença significativa entre os trechos 1 e 4 , trechos 5 e 4 , trechos 5 e 3 e trechos 5 e 9 , conforme apresentada na figura 2.

\section{DISCUSSÃO}

Neste estudo, mediante os resultados levantados, foi possível dimensionar o desconhecimento de vocabulário receptivo de estudantes de Fisioterapia durante a leitura da CIF. Como resultado direto desse processo de avaliação do reconhecimento lexical dos estudantes no contexto da CIF, foi criado um glossário que pôde ser utilizado em exercícios didáticos, com estratégias metacognitivas de enriquecimento lexical, bem como em consultas para aquisição de habilidades e competências na descrição dos estados e condições de saúde individuais e populacionais.

A partir da familiaridade com alguns vocábulos citados, poderíamos observar o uso da estratégia metacognitiva, que é a capacidade de um indivíduo inferir a partir de vocábulos familiares ou já experimentados, podendo fazer inferências corretas ou incorretas, a depender do nível de interpretação e consistência do conhecimento prévio.

Nossos resultados mostraram que uma quantidade mínima de estudantes $(18 \%$ dos $30 \%$ que arriscaram anotar um significado) conseguiu inferir significado com a estratégia metacognitiva. Tal estratégia vai além da cognitiva, pois ela é caracterizada por funções automatizadas de reconhecimento para identificar as informações mais objetivas que estão explícitas no texto. A metacognição se caracteriza pela capacidade de inferir e interpretar, fazer reflexões a partir de questões, sendo dividida em monitoramento, autoexplicação e justificativa ${ }^{17}$. 
No monitoramento, seja enquanto se lê ou após a leitura, o leitor avalia se há inconsistências em sua compreensão de parte do texto ou dele como um todo. Essas inconsistências podem ser empíricas, quando contradizem o conhecimento de mundo do leitor, ou lógicas, quando há proposições contraditórias no texto. A partir da detecção de suas dificuldades, o leitor pode eleger estratégias para remediá-las. O leitor pode fazer uso do monitoramento no nível local enquanto lê partes do texto, ou no nível global, tomando o texto como um todo, durante ou após a leitura ${ }^{17,18}$.

No tocante à autoexplicação, são as inferências que vão além do texto, gerando nova informação, estando excluídos dessa categoria outros tipos de comentários, tais como paráfrases do texto. Ademais, em relação às justificativas, após responder a perguntas relativas à compreensão do texto lido, podem ser solicitadas ao leitor justificativas para as suas respostas. Estas justificativas consistem na explicação das bases de suas respostas ${ }^{17}$. Poucos estudantes (30\%) arriscaram explorar suas capacidades metacognitivas ou não tinham condições de fazer tal inferência.

Para que as estratégias metacognitivas se desenvolvam, várias habilidades são necessárias, principalmente aquelas envolvidas no processamento fonológico, sendo comprovada por meio de estudos experimentais em crianças que revelam que os problemas em leitura e escrita comprometem a consciência fonológica (habilidade de reconhecer e pronunciar as sílabas e fonemas), nomeação (capacidade de acessar a forma fonológica da palavra, figura ou números, dentre outros), memória de curto prazo de conteúdo oral (o armazenamento, por curtos períodos de tempo, da linguagem falada) e vocabulário (receptivo ou expressivo) ${ }^{18}$.
Uma estratégia que possibilita o desenvolvimento dessas habilidades, já bastante difundida na literatura, é o mapa conceitual, que é uma ferramenta de ensino/aprendizagem que requer a capacidade de analisar, sintetizar, experimentar e hierarquizar conceitos para facilitar a metaaprendizagem. Favorece a integração e ampliação dos conhecimentos, bem como possibilita o desenvolvimento do pensamento crítico na descrição dos estados e condições de saúde. Tal método de aprendizagem foge da forma tradicional de ensinar e favorece as etapas fisiológicas do aprendizado, tornando-o pleno e eficiente ${ }^{19,20}$.

De acordo com os nossos resultados, nota-se que os trechos T3, T4 e T9 indicaram um menor reconhecimento lexical receptivo pelos estudantes (figura 2), sendo o T4 o trecho de maior desconhecimento lexical com 42 vocábulos declarados como desconhecidos. Tal trecho está relacionado com o componente de funções e estruturas do corpo (OMS, 2004)1. O T4 foi seguido pelo T3, que assim como o T4 abordam termos bem específicos de anatomia e fisiologia humana, contendo também vocabulário que descreve sinais e sintomas de determinadas disfunções que ainda são desconhecidas pelos estudantes que, apesar de já terem realizado disciplinas biológicas que utilizam tais campos lexicais, podem ainda não ter suficientemente treinado os vocábulos para garantir o seu efetivo aprendizado e compreensão (tabela 1).

Desse modo, o mapa conceitual, que é um exemplo de estratégia de aprendizado que aborda o conceito heurístico, pode ser aplicado no processo de reconhecimento de palavras quer por via lexical, quer por via fonológica, ou ainda por acesso ao léxico ortográfico armazenado na memória de longo prazo $^{18,19,21}$. Ao que parece, o mapa conceitual seria 
um método de estratégia de aprendizado pelo qual os estudantes com menor reconhecimento lexical nos trechos T3, T4 e T9, conseguiriam descobrir, aprender e destrinchar os conceitos dos vocábulos desconhecidos.

Por sua vez, o T9, é um trecho composto por descrição das utilizações, das diretrizes éticas, das orientações e das exemplificações do uso da CIF (tabela 1). O desconhecimento de vocábulos nesse trecho poderia ser justificado pela falta de conhecimento da CIF e seu raciocínio clínico, uma vez que, para a maioria dos estudantes é nessa disciplina que eles entram em contrato pela primeira vez com a classificação. Tal conhecimento será apresentado e elucidado no decorrer da disciplina objeto de investigação no estudo. Cabe ainda ressaltar que os trechos mais desconhecidos (T3, T4 e T9), conforme representado na figura 2, ainda apresentam vocabulário que não é praticado cotidianamente pelos estudantes que ainda não desenvolveram muitas práticas de campo, assim, estão distantes do campo lexical usual deles.

Essa hipótese corrobora estudos ${ }^{10,22}$ que verificaram um melhor desempenho em recepção de vocabulário quando por meio de habilidades acadêmicas exigidas em variadas atividades pedagógicas de aprendizado realizadas em cenários de atuação prática. Nesse contexto, tais cenários propiciam aos estudantes o aperfeiçoamento e ampliação lexical. Assim, garantem aos estudantes a oportunidade real de aprender novo vocabulário e conhecer sua forma e significado em contexto de uso.

Em contrapartida, nos trechos em que foram observados menos vocábulos desconhecidos (quadro da direita na figura 1) estão presentes textos dos componentes de atividade e participação e fatores ambientais ${ }^{1}$ (tabela 1 ), que utilizam um vocabulário mais comum do campo lexical das atividades humanas que são facilmente reconhecidas, por esta razão poderiam estar no campo lexical mais usual ao estudante. Tal suposição é sustentada por Piccolo e Salles et al. ${ }^{22}$, que investigaram a relação entre leitura, memória de trabalho, quociente de inteligência e vocabulário em crianças. Os resultados evidenciaram que há uma relação estreita entre memória de trabalho, vocabulário e outros processos cognitivos no processo de leitura. Ainda, quando foram incluídas somente crianças sem qualquer deficit intelectual, a memória de trabalho visuoespacial e o vocabulário contribuíram mais para o desempenho em compreensão de leitura. Ou seja, o estímulo recebido do contexto do ambiente em que o estudante está inserido seria o agente na capacidade de compreender uma informação e adquirir o vocabulário e seu significado.

Dos estudantes avaliados, 89,1\% (33 estudantes) ingressaram na UnB no período 2/2013 e encontravam-se, portanto, na etapa do curso em que a maioria das disciplinas dispostas na matriz curricular utiliza vocábulos dos componentes biológicos da CIF. No entanto, existem também disciplinas de cunho social e epidemiológico que abordam o contexto coletivo da saúde e a compreensão do trabalho do profissional da saúde, o que mostra a ampliação do léxico no contexto da saúde coletiva, elucidada pelo modelo de atenção biopsicossocial que é empregado na CIF. Tal observação reforça a mudança da visão centrada na doença para um foco na funcionalidade ampliada para além dos componentes biológicos como elemento essencial da saúde $e^{2,3,5,16}$.

A quantidade de vocábulos elencados como desconhecidos podem expressar o nível do léxico mental dos estudantes ${ }^{6,23,24}$, que reflete o período do curso em que os estudantes se encontram, conhecendo vocábulos mais triviais e de mais baixa complexidade lexical no campo da saúde. Os vocabulários mais desconhecidos podem até estar presentes nos contextos das disciplinas que os estudantes já cursaram ou estão cursando, contudo, a prática de utilização de tal linguagem ainda pode não ter sido incorporada no léxico mental. Ainda, os vocábulos desconhecidos podem fazer parte do contexto de disciplinas que ainda serão cursadas. 
Neste estudo, os sujeitos estão inseridos em atividades universitárias que, supostamente, implicam uma rotina diária de leitura. As circunstâncias sociais e culturais são bastante ricas e diversificadas e, supostamente, com foco no campo lexical da saúde. O cenário apresentado tornaria possível a imersão nesse universo de familiarização com o novo vocabulário.

Tal visão está de acordo com os estudos ${ }^{7,10}$ que confirmaram que, com o avançar dos anos de vida, também se aumenta o vocabulário, fato esse inerente ao próprio desenvolvimento fisiológico e cognitivo. No entanto, nesses estudos, constatouse que as crianças mais velhas obtiveram um desempenho menor do que as crianças mais novas, verificando que o vocabulário depende de um avanço coeso com os estímulos recebidos do ambiente, da cultura e da sociedade em que o indivíduo está inserido, ou seja, somente ter mais tempo de vida não é garantia absoluta de maior reconhecimento lexical para adultos.

Como a CIF aplica em seu texto vocábulos desde os mais simples aos mais complexos, desde os mais usuais aos mais específicos do campo lexical da saúde, a depender do componente considerado (função ou estrutura do corpo, atividade e participação e fatores contextuais) e do detalhamento da informação (capítulos e desdobramento dos códigos raízes), supostamente encontraríamos vocábulos mais ou menos fáceis de serem reconhecidos, cujo reconhecimento se apoiariam mais ou menos em um campo lexical automático ou em formação.

Ao que parece, o campo lexical automático acessado pelos estudantes desta amostra não está ainda amadurecido em termos de vocabulário específico do campo lexical da saúde, como já discutido. Assim, o que poderia estar determinando o nível de reconhecimento automático seriam os processos condicionados ao longo da vida de práticas de leitura e das circunstâncias sociais e culturais, relacionadas com o ambiente no qual o indivíduo estaria inserido ${ }^{21}$.
Este estudo não avaliou previamente o nível de leitura dos estudantes, uma limitação para análises mais amplas, porém se sabia o fluxo de progressão no curso que o estudante se encontrava. A bagagem de leitura não necessariamente estaria relacionada com o texto da CIF, mas no ambiente e no social de convívio de cada estudante que seria determinístico na influência da prática de leitura.

A importância da leitura na formação lexical é enfatizada por Freire ${ }^{25}$ ao discorrer sobre a necessidade da leitura. Segundo ele, a prática da leitura está no gosto pelo ler, que é desenvolvido na medida em que os assuntos estejam de acordo com o interesse e a necessidade do leitor. Isso estabelece uma troca de intimidade e consciência entre educadores e estudantes. A educação tem por dever o estímulo ao desenvolvimento da leitura crítica, com a participação consciente dos educadores e educandos na construção da sociedade e de profissionais.

Nossos resultados sugerem que os estudantes investigados ainda não possuem a atividade complexa de reconhecer as palavras para acessar o léxico mental individual no contexto da CIF. Tal fato pode ser explicado segundo a lógica apontada por Monteiro e Soares ${ }^{21}$, que descrevem ser a fluência e a compreensão entidades distintas. Segundo os autores citados, fluência é a capacidade de reconhecimento das palavras que levam à compreensão e, irá depender de diversos processos interligados para fornecer um contexto macroestrutural do texto ${ }^{10,11}$. Logo, o fato de termos identificado 167 vocábulos desconhecidos poderia mostrar que apesar da amostra ser fluente na língua portuguesa, ela apresenta dificuldade de fluência no campo lexical de alguns contextos presentes no texto da CIF. O estudante provavelmente necessitaria de maior tempo para absorver o modelo e contextos presentes no texto da CIF, pois, no período do curso em que eles se encontram, ainda seriam necessárias práticas de vivência relacionadas com a sua futura atuação para incorporar novos aprendizados, bem 
como concretizar o aprendizado das disciplinas que já foram cursadas.

Dessa forma, a aplicação das estratégias de reconhecimento de palavras, segundo Seabra e Dias $^{18}$, constituem em logográfica, alfabética e ortográfica. Para uso dessas estratégias, cabe às habilidades de processamento fonológico da consciência fonológica e compreensão auditiva - tal processo é favorecido pela extensão de vocabulário do indivíduo, ou seja, saber reconhecer cada vocábulo e seu significado. A aplicação dessas estratégias pode se dar por meio da metodologia ativa, que tem sua visão educacional arquitetada no princípio da autonomia, colocando os próprios estudantes como fundamentais agentes de seu aprendizado; bem como trabalhar o exercício contínuo de motivação e estímulo à reflexão e produção de conhecimento para promover seu próprio desenvolvimento ${ }^{26}$.

Uma outra limitação deste estudo foi o fato de não termos medido a compreensão do que os estudantes leram, visto que foi somente medido o reconhecimento lexical. Isso não nos permite inferir o quanto essa falta de vocabulário foi significativa para compreender. Tal abordagem deve ser considerada em trabalhos futuros.

Uma forma de avaliação da compreensão encontrada na literatura é a proposta por Taylor ${ }^{27}$, que desenvolveu o Teste de Cloze - instrumento amplamente utilizado em estudos de linguagem que se mostra eficaz, prático, de fácil aplicação e de alto índice avaliativo do desempenho acadêmico para estudantes. Por meio desse instrumento, é possível obter indicadores de que os estudantes com melhores percentuais testados exibem os melhores resultados nas práticas avaliativas das disciplinas que cursam. Além disso, constatam que o baixo nível de compreensão é uma importante barreira na dificuldade de leitura e de aprendizagem, permitindo inferir que o sucesso na graduação em nível superior está diretamente relacionado com o amadurecimento do estudante enquanto leitor ${ }^{28,29,30}$.

Por último, conjecturamos ser importante que o estudante seja inserido precocemente, no decorrer da graduação, nos cenários de prática em que ele utilizaria o campo lexical da CIF. Por meio das estratégias metacognitivas e de reconhecimento de palavras estimulados nos cenários de prática, o léxico desejado seria evocado repetitivamente à memória de trabalho e, possivelmente, se consolidaria em memória de longa duração. Tal hipótese se sustenta no fato de que, em uma trajetória de atividades didáticas percorrida pelo estudante unicamente em salas de aulas e com sistemas de avaliação puramente teóricos, o estudante não aplica em diferentes contextos seu vocabulário, não favorecendo o reconhecimento, compreensão e expressão das palavras e seus significados.

\section{CONCLUSÃO}

Conclui-se, com este estudo, que quase duas centenas de vocábulos presentes no texto da CIF são desconhecidos por estudantes de Fisioterapia com um menor reconhecimento lexical dos estudantes em formação nos trechos relacionados com os componentes de funções e estruturas do corpo. Sugere-se a necessidade de utilizar estratégias de aprendizagem que incluam atividades contextualizadas em cenários reais de prática para obter uma construção do conhecimento da CIF cujo modelo de organização taxonômica pode ser aplicado no raciocínio clínico da prática fisioterapêutica e útil no percurso acadêmico.

\section{AGRADECIMENTOS}

Nós agradecemos às estudantes do curso de Fisioterapia da FCE da UnB Raquel C. M. Cavalcanti, Fernanda R. Medeiros e Tatiana I. S. Oliveira por suas contribuições durante os procedimentos metodológicos de coleta de dados; bem como à Professora Juliana F. F. Romão que foi a terceira julgadora no processo de avaliação da aproximação do significado sugerido pelos participantes ao significado real do vocábulo. 


\section{REFERÊNCIAS}

1. Organização Mundial de Saúde. Classificação Internacional de Funcionalidade, Incapacidade e Saúde. 2004.

2. Araújo ES. A Classificação Internacional de Funcionalidade, Incapacidade e Saúde ( CIF ) em Fisioterapia : uma revisão bibliográfica [dissertação]. São Paulo (SP): Universidade de São Paulo; 2008

3. Martins EF, de Sousa PH, Barbosa PH, de Menezes LT, Costa AS. A Brazilian experience to describe functioning and disability profiles provided by combined use of ICD and ICF in chronic stroke patients at home-care. Disability and Rehabilitation 2011; 33(21-22): 2064 - 74.

4. Castaneda L, Bergmann A, Bahia L. A Classificação Internacional de Funcionalidade, Incapacidade e Saúde: uma revisão sistemática de estudos observacionais. Rev Bras Epidemiol 2014; 17(2): 437-451.

5. Araújo-Barbosa PHF. Modelagem e simulação de informações do estado de saúde codificadas pela Classificação Internacional de Funcionalidade, Incapacidade e Saúde: requisitos e subsídios para sistemas de informação em saúde [dissertação]. Brasília (DF): Universidade de Brasília, 2016.

6. Pedrosa BAC, Dourado JS, Lemos ST. Desenvolvimento lexical, alterações fonoaudiológicas e desempenho escolar: revisão de literatura. Revista CEFAC 2015; 17(5): 1633-1642.

7. Araújo MVM, Marteleto MRF, Schoen-Ferreira TH. Avaliação do vocabulário receptivo de crianças préescolares. Estudos de Psicologia 2010; 27(2): 169-176.

8. Associação Brasileira de Ensino em Fisioterapia. Reformulação das Diretrizes Curriculares Nacionais dos Cursos de Graduação em Fisioterapia. [Internet]. [acessado 2016 out 30]. Disponível em: http://revista. redeunida.org.br/ojs/index.php/cadernos-educacao-saude-fisioterapia.

9. Brasil. Resolução CNE/CES 4, de 19 de Fevereiro de 2002. Institui diretrizes Nacionais do Curso de Graduação em Fisioterapia. Ministério da Educação, 2002. [Internet] [acessado 2016 nov 01]. Disponível em: http://portal.mec.gov.br/cne/arquivos/pdf/CES042002.pdf.

10. Nalom AFO, Soares AJC, Cárnio MS. A relevância do vocabulário receptivo na compreensão leitora. CoDAS 2015; 27(4): 333-338.

11. Salles JF, Parente MAMP. Processos Cognitivos na Leitura de Palavras em Crianças : Relações com Compreensão e Tempo de Leitura. Psicologia: Reflexão e Crítica 2001; 15(2): 321-331.

12. Unesco. Relatório de Monitoriamento Global de EPT 2013/4. Organização das Nações Unidas para a Educação, a Ciência e a Cultura. 2014.

13. Brasil. Relatório de Educação para todos no Brasil. Ministério da Educação. 2014.

14. Bardin L. Análise de conteúdo. Lisboa: Ediçoes 70, v. 70, 1977. 
15. Caregnato RCA, Mutti R. Pesquisa qualitativa: análise de discurso. Texto \& Contexto Enfermagem 2006; 15(4): 679-684.

16. Universidade de Brasília. Relatório de Autoavaliação Institucional 2015. Universidade de Brasília, 2015. 17. Hodges LVSD, Nobre APM. O uso de estratégias metacognitivas como suporte à compreensão textual. Revista Eletrônica de Educação 201; 6(2): 476-490.

18. Seabra AG, Dias N. Reconhecimento de palavras e compreensão de leitura : dissociação e habilidades linguístico-mnemônicas preditoras. Revista Neuropsicología Latinoamericana 2012; 4(1): 43-56.

19. Bittencourt GKGD, Nóbrega MML, Medeiros ACT, Furtado LG. Mapas conceituais no ensino de pósgraduação em enfermagem: relato de experiência. Revista Gaúcha de Enfermagem 2013; 34(2): 172-176. 20. Dornelas LF, Duarte NMC, Magalhâes LC. Atraso do desenvolvimento neuropsicomotor: mapa conceitual, definições, usos e limitações do termo. Revista Paulista de Pediatria 2015; 33(1): 88-103.

21. Monteiro SM, Soares M. Processos cognitivos na leitura inicial: relação entre estratégias de reconhecimento de palavras e alfabetização. Educação e Pesquisa 2014; 40(2): 449-465.

22. Piccollo LR, Salles JF. Vocabulário e memória de trabalho predizem desempenho em leitura de crianças. Psicologia: Teoria e Prática 2013; 15(2): 180-191.

23. Coltheart M, Rastle K, Perry C, Langdon R, Ziegler J. DRC: A dual route cascaded model of visual word recognition and reading aloud. Psychological Review 2001; 108(1): 204-256.

24. Corso HV, Salles JF. Relação entre leitura de palavras isoladas e compreensão de leitura textual em crianças. Letras de Hoje 2009; 44(3): 28-35.

25. Freire PA. A importância do ato de ler: em três artigos que se complementam. São Paulo, 1982.

26. Mitre SM, Siqueira-Batista R, Girardi-de-Mendonça JM, Morais-Pinto NM, Meirelles CAB, Pinto-Porto $\mathrm{C}$, et al. Metodologias ativas de ensino-aprendizagem na formação profissional em saúde: debates atuais. Ciência \& Saúde Coletiva 2008; 13(2): 2133-2144.

27. Taylor WL. Cloze procedure: A new tool for measuring readability. Journalism Quarterly 1953; 30: 434438.

28. Oliveira R, Oliveira KL. Leitura e condições de estudo em universitários ingressantes. Revista de Psicologia da Vetor Editora 2007; 8(1): 51-59.

29. Oliveira KL, Santos AAA, Primi R. Estudo das relações entre compreensão em leitura e desempenho em disciplinas na universidade. Revista Interação em Psicologia 2003; 7(1): 19-25.

30. Souza NA, Coruchovitch E. Mapas conceituais: estratégia de ensino/aprendizagem e ferramenta avaliativa. Educação em Revista 2010; 26(3): 195-217. 